\title{
Title:
}

\section{Anterior and Posterior Corneal Elevation after Orthokeratology, Standard and Customized LASIK Surgery}

\section{Running head:}

\section{Front and Back Corneal Elevation after CRT and LASIK}

\section{António Queirós, PhD, ${ }^{1}$ César Villa-Collar, FAAO, PhD, ${ }^{2}$ Ángel Ramón Gutiérrez, MD, PhD, ${ }^{3}$ Jorge Jorge, PhD, ${ }^{1}$ Maria Sameiro Ribeiro-Queirós, ${ }^{4}$ Sofia Claudia Peixoto-de-Matos, OD, ${ }^{5}$ José Manuel González-Méijome, FIACLE, PhD ${ }^{1}$}

${ }^{1}$ Clinical \& Experimental Optometry Research Lab-CEORLab. Center of Physics (Optometry), School of Sciences, University of Minho, Braga, Portugal.

${ }^{2}$ Department of Optica and Optometria. European University de Madrid, Spain.

${ }^{3}$ Department of Ophthalmology, University of Murcia, Murcia, Spain.

${ }^{4}$ School Gonçalo Sampaio, Department of Mathematics, Póvoa de Lanhoso, Portugal.

${ }^{5}$ Óptica Queirós, Póvoa de Lanhoso, Portugal.

\section{Corresponding Author:}

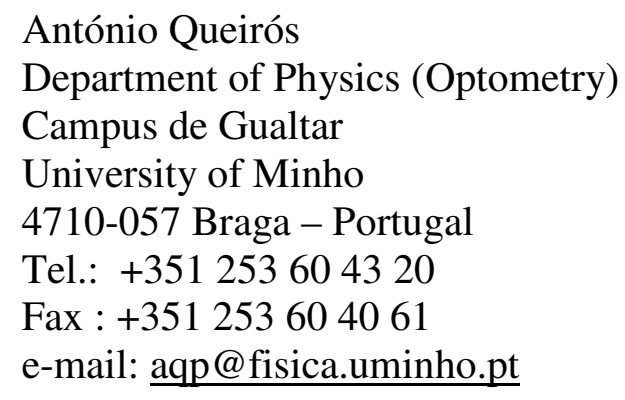

Disclosure: The authors have no proprietary interest in any of the instruments or materials mentioned in this article. 


\begin{abstract}
Purpose: To quantify the changes in the elevation topography of the front and back corneal surface after three different refractive treatments for correcting myopia with standard and custom LASIK and orthokeratology using corneal refractive therapy (CRT).
\end{abstract}

METHODS: We evaluated 20 eyes undergoing orthokeratology for correction of myopia spherical equivalent (Mean $\pm \mathrm{SD}=-3.41 \pm 0.76 \mathrm{D}), 18$ eyes undergoing custom LASIK surgery (Mean $\pm \mathrm{SD}=-4.14 \pm 0.89 \mathrm{D})$ and 23 undergoing standard LASIK (Mean $\pm \mathrm{SD}=-3.61 \pm 0.67 \mathrm{D})$. Values of front and back corneal surface were derived from Pentacam (Oculus, Inc. GmbH, Wetzlar, Germany) before and at least 3 months after each treatment, in the center of the cornea and 4 points to each side of the horizontal meridian at intervals of $1 \mathrm{~mm}$.

RESULTS: Corneal elevation data before treatment were not statistically different between patients in either group $(P>0.070$, for back and front elevation). After treatment, both surgical procedures increased significantly the positive value of the front elevation beyond the area of $6 \mathrm{~mm}$. The opposite trend was found within the central $5 \mathrm{~mm}$ of the cornea, presenting a statistically significant decrease in elevation $(P<0.001)$. In the case of orthokeratology, the elevation suffered minor but a statistically significant reduction in the central region $(P<0.001)$. On the back surface, the elevation did not undergo statistically significant alterations in any of the procedures and none of the items discussed $(P>0.285)$.

CONCLUSIONS: Differences in front corneal elevation changes between LASIK and orthokeratology reveal a much different mechanism for producing corneal power subtraction. The back corneal surface does not suffer significant changes after surgical and nonsurgical treatments for the correction of myopia. 
Keywords: Corneal refractive therapy; orthokeratology; refractive surgery LASIK; corneal elevation.

\section{INTRODUCTION}

Corneal topography is most commonly defined in terms of radius of curvature or refractive power. However elevation maps have clinical interest for eye care practitioners to evaluate the shape of the cornea before surgical procedures looking for indications of potential ectatic signs to prevent future complications. ${ }^{1}$ As such, several ectatic indices have been derived based on corneal elevation data. As other topographers, Pentacam allows the measurement of several parameters of both the front and the back corneal surfaces. As opposed to Placido disk systems where surface curvature is measured by analyzing the reflex or a given pattern (the Placido disk system) Pentacam uses Scheimpflug photography mainly to obtain sharp images of the transparent tissue under evaluation in order to reconstruct a three-dimensional profile from which topographical data is obtained. ${ }^{2,3}$ Analysis of corneal parameters with Pentacam has already been reported in normal eyes, ${ }^{4}$ keratoconic eyes ${ }^{5}$ and post-LASIK eyes. $^{6}$

Considering the subtle changes that can be detected through elevation data, in this study we aim to compare the values of front and back elevation data in order to establish differences between the overall corneal contour after three different refractive surgical (custom and standard LASIK) and non-surgical (orthokeratology) procedures to correct myopia. To our knowledge, no other study has evaluated elevation data in these three treatments before.

\section{MATERIAL AND METHODS}

\section{$\underline{\text { Subjects and inclusion criteria }}$}


Sixty-one patients were recruited to participate in this study as candidates to undergo orthokeratology using corneal refractive therapy (CRT, $n=20)$, standard LASIK $(\mathrm{SL}, \mathrm{n}=23)$ and customized LASIK $(\mathrm{CL}, \mathrm{n}=18)$ at the Ophthalmology Clinic Novovision (Madrid, Spain). After explaining the nature of the study, each patient signed a consent form before being enrolled. The research followed the tenets of the Declaration of Helsinki and was reviewed and approved by the Scientific Committee of the School of Sciences of Minho University (Portugal).

Only patients with myopia between $-2.25 \mathrm{D}$ and $-5.00 \mathrm{D}$ and astigmatism below $1.00 \mathrm{D}$ were included, in order to match the range of refractive errors more commonly treated with CRT. No patient had any history of ocular disease or had undergone previous ocular surgery. Complete optometric and ophthalmological examinations were performed before surgical and non-surgical correction of myopia with the aforementioned techniques. All patients had satisfactory results after the interventions with respect to residual refractive error $(\leq \pm 0.50 \mathrm{D})$, visual acuity, regularity and centering of the treatment zone. A minimum of 3 months after treatment was required to guarantee that topography was completely stable. ${ }^{7,8}$

After that, patients should have demonstrated to be successfully treated regarding to residual refractive error, visual acuity $(\geq 20 / 20$ or higher uncorrected visual acuity), surface regularity and centering of the treatment zone (less than $0.5 \mathrm{~mm}$ of decentration) before being elected for this study.

\section{LASIK surgery}

The type of ablation was central with an optic zone of $6.50 \mathrm{~mm}$ for all the laser in situ keratomileusis (LASIK) cases, and a transition zone of $0.30 \mathrm{~mm}$ for the spherical cases in the standard LASIK group and $1.25 \mathrm{~mm}$ for astigmatic corrections and customized LASIK procedures. 
Surgical routine for LASIK surgery was according to international standards and the commonly accepted criteria for refractive surgery procedures were followed. After a $120 \mu \mathrm{m}, 9.5 \mathrm{~mm}$ diameter flap creation with a Hansatome microkeratome (Chiron Vision, model 2765; Bausch \& Lomb, Claremont, California, USA), standard and customized ablation profiles were produced using the Allegretto Wave Eye-Q - $400 \mathrm{~Hz}$ - (Wavelight, Erlangen, Germany). All surgical procedures were uneventful and considered successful.

\section{Corneal refractive therapy lens characteristics}

The rigid gas permeable material used for the $\mathrm{CRT}^{\mathrm{TM}}$ lenses (paflufocon $\mathrm{D}$, Dk=100 barrer - Paragon Vision Sciences, Mesa, AZ, USA) with parameters, base curve radius $(\mathrm{BCR}=8.57 \pm 0.34 \mathrm{~mm} \quad[8.00,9.20])$ return zone depth $(\mathrm{RZD}=540.63 \pm 22.90 \mu \mathrm{m}[500,575])$ and landing zone angle $(\mathrm{LZA}=32.38 \pm 1.19$ degrees [31,35]). Trial lenses were derived from nomograms in the form of sliding tables produced by the manufacturer Paragon CRT sigmoid reverse geometry contact lens ${ }^{9}$.

\section{$\underline{\text { Outcomes }}$}

For those patients who satisfied the inclusion criteria, front and back corneal surface topographies were obtained with Pentacam (Oculus, Inc. GmbH, Wetzlar, Germany). Operation modes and repeatability of the instrument are described in the literature. ${ }^{10-12}$ The instrument was calibrated before each measuring session.

Topographical data along the horizontal meridian were collected, over a $8 \mathrm{~mm}$ corneal diameter in $1 \mathrm{~mm}$ steps, in the center of corneal topography $(\mathrm{C}), 4 \mathrm{~mm}$ in the nasal corneal $(\mathrm{N} 1, \mathrm{~N} 2, \mathrm{~N} 3, \mathrm{~N} 4)$ and 4mm in the temporal corneal $(\mathrm{T} 1, \mathrm{~T} 2, \mathrm{~T} 3, \mathrm{~T} 4)$ using the elevation map from the computer display (elevation data was obtained using the Floating Point option). Topographic data was obtained manually for each location. In order to improve reliability of readings, only maps with coverage of the central $8 \mathrm{~mm}$ in 
the horizontal meridian and with no irregularities during acquisition was considered. Our origin of measurements was the keratometric center, where the grid of the topography map has the $(0 ; 0)$ coordinates. Pre-treatment Best Fit Sphere (BFS) was calculated for each cornea automatically by Pentacam. The same BFS was again used for each cornea after intervention in order to maintain the same reference surface for subsequent comparison. BFS was fitted to the central $8 \mathrm{~mm}$ of the cornea.

\section{$\underline{\text { Statistical Analysis }}$}

SPSS software package v.17 (SPSS Inc., Chicago, IL, USA) was used for statistical analysis. Kolmogorov-Smirnov Test was applied in order to assess normality of data distribution. ANOVA and Kruskal-Wallis were used to evaluate potential differences in baseline data among three treatments groups altogether (CRT, SL and CL) for normally or non-normally distributed variables, respectively. This allowed us to establish whether the treatment groups are comparable or not in terms of baseline values. For multiple comparisons, values of statistical significance were adjusted using Bonferroni post-hoc test. Paired Samples T-test and Wilcoxon were used to compare variables between pre- and post-treatment in each group separately, for normally or non-normally distributed variables, respectively. This led us to conclude whether or not topography locations show statistically significant changes after each treatment. For statistical purposes, a $p$ value less than 0.05 was considered statistically significant.

\section{RESULTS}

Sixty one right eyes of 61 patients, mean age of $28.3 \pm 9.8$ years (range from 16 to 42) out of which 29 were female, were included in the study. 
Table 1 shows the pre-treatment demographic data. Mean values and standard deviation for the three groups of selected patients are displayed for each of the variables. Statistically significant differences were found for the spherical equivalent among the three clinical groups $(P=0.020$, Kruskal-Wallis Test), but not for the astigmatic components $(P>0.288$, Kruskal-Wallis Test). The elevation baseline data were not statistically different between treatments in either of the 9 points under evaluation on the front or back surface.

In table 2 mean value, standard deviation and the value of statistical significance for corneal topography (front and back) differences between pre, post and pre minus post-treatment are presented separately for each technique. For the front corneal surface, after treatment, both surgical procedures increased significantly the positive value on the front surface elevation at 3 and $4 \mathrm{~mm}$ distance, while elevation became negative in the region of the central 4-5 $\mathrm{mm}$. In all cases the changes were statistically significant $(P<0.001)$ for both surgical procedures. In the case of orthokeratology, the elevation suffered minor but statistically significant changes in the central region. Figure 1 present a graphical representation of elevation data from the front corneal surface for the differences between baseline values and post treatment. On the back surface, the elevation did not undergo statistically significant alterations in any of the procedures and none of the items discussed. Figure 2 present a graphical representation of elevation data from back corneal surface between the procedures post and pretreatment. For the back corneal surface, no statistically significant differences were found among the three clinical groups except for $\mathrm{N} 2$ in SL ( $P=0.036$, paired sample t-test) and for T2 in CL $(P=0.011$, paired sample t-test $)$. 


\section{DISCUSSION}

From a qualitative point of view, the topographic changes that take place at the front corneal surface after orthokeratology and LASIK refractive surgery might seem similar when looking at the curvature maps. Irrespective of the dimensions of the treated zones and the mechanism that drives the increase corneal power at the transition zone between central treated and peripheral non treated zones, ${ }^{13}$ the quantitative analysis of elevation profiles has shown remarkable differences between surgical and non-surgical treatments.

As an intuitive hypothesis derived from the mechanisms involved in peripheral steepening of the cornea with orthokeratology, ${ }^{14,15}$ we could postulate that while power increase is justified in orthokeratology by an increment of paracentral elevation, caused by tissue re-distribution. Different findings between surgical vs contact lens corneal reshaping regarding to peripheral elevation changes could be at least in part be a result of the biomechanical response of the cornea after LASIK. Dupps and Wilson postulated that a redistribution of biomechanical forces will drive a significant increase in midperipheral elevation, which is coincidental with the results presented here. ${ }^{16}$ Such changes won't be present after orthokeratology where the goal is to produce a flattening of the front corneal surface with minimal impact in peripheral elevation, just limited to the increase induced by redistribution of epithelial tissue ${ }^{15}$ and edematous response ${ }^{17}$ that might be on the order of few microns. However, it is not likely that such a potential increase in peripheral elevation will reach the values observed here. In comparison, the decrease in elevation at center in LASIK treatments is well below the ablation depth expected for an average treatment in the order of 3 to 4 diopters of myopia. These effects of increased peripheral elevation are potentially due to shifts in the placement of the BFS along the z-axis in post-LASIK corneas using the float point methodological 
approach with Pentacam. Considering this limitation, we must recognize that the results from the present study must be considered as a clinically representative report of the data expected after orthokeratology and LASIK when using Pentacam, rather than an analysis of the anatomical changes in the three-dimensional structure of the corneal tissue.

One limitation of the study is that the baseline refractive error in the custom Lasik group was significantly higher than in the remaining groups and the correction induced in the three different groups were significantly different what could induce significant changes in terms of the elevation changes documented in the present work. However, this does not preclude the derivation of remarkable conclusions from this study. Moreover, this fact seems to be quite irrelevant when we observe the similarity in the elevation changes between standard and custom LASIK (despite their different baseline M) and the difference between standard Lasik and orthokeratology (despite absence of statistically significant differences in baseline $\mathrm{M}$ values). Moreover, even when standard and custom LASIK groups underwent significantly different refractive treatments, they showed a highly consistent pattern in terms of elevation changes. So, despite this limitation, the results of the present study support the marked difference in the behavior of the front corneal surface after surgical and non-surgical treatments for the correction of myopia.

The other major outcome of the present study is to confirm in this clinical setting that the back corneal surface remains quite stable after LASIK and orthokeratology. This agrees with the results obtained by Grewal et al. ${ }^{18}$ for patients undergoing LASIK using different methods for flap creation and Ha et al. after PRK. ${ }^{19}$ These studies had similar outcomes despite had methodological approaches to derive elevation from Pentacam; Ha et al. ${ }^{19}$ used float point facility to determine the position of the BFS, 
while Grewal et al. did not. ${ }^{18}$ In the present study we used the float point facility. The limitations related to this approach have already been discussed.

Previous studies had reported a steepening of the back corneal surface measured with Orbscan II slit-scanning system. ${ }^{20-23}$ However, two recent reports from Nawa et al. and Cheng et al., have showed that the changes in the refractive power of the back corneal surface might be explained by an artifact where the back corneal surface observed through the front one might appear smaller and steeper. ${ }^{24,25} \mathrm{Ha}$ et al. have evaluated posterior elevation after PRK. ${ }^{19}$ In their study, ${ }^{19}$ while significant changes in elevation were obtained with Orbscan II, no differences were found with Pentacam. Although not directly related with the issue addressed in the present work, this artifact might also be linked to the overestimation of peripheral corneal thickness by Orbscan II compared to ultrasound pachometry as documented by Gonzalez-Méijome et $a{ }^{26}{ }^{26}$ In fact, as Orbscan II relies on front corneal curvature and slit section imaging to derive the back corneal surface and corneal pachometry, this explanation is plausible.

The present results further confirm the absence of changes in the back corneal surface in terms of elevation, suggesting that elevation maps instead of curvature maps are more valuable in post-surgical corneal evaluation. Results from the present study are also in agreement with those recently presented by Perez-Escudero et al. on porcineplastic cornea model of LASIK refractive surgery. ${ }^{27}$

In summary, the results from the present study confirm in a clinical sample that 1) elevation and curvature represent much different features of the geometrical nature of the cornea, particularly after corneal refractive procedures; 2) changes in elevation of the front corneal surface are 2 to 3 times greater in LASIK than orthokeratology either in the central location and the most peripheral locations (annular are of $8 \mathrm{~mm}$ ) along the 
horizontal meridian; 3) back corneal surface remains stable in terms of elevation after LASIK and orthokeratology.

Acknowledgements: This work was supported by a grant from the Science and Technology Foundation (FCT) of Ministry of Science and Superior Education (MCES) (European Social Funding). Doctoral Fellowship (AQ) number SFRH/BD/61768/2009.

Table 1. Descriptive statistics (mean \pm S.D.) for population data collection

\begin{tabular}{|c|c|c|c|c|}
\hline & $\begin{array}{l}S L(n=23) \\
\text { mean } \pm s d\end{array}$ & $\begin{array}{l}\mathrm{CL}(\mathbf{n}=\mathbf{1 8}) \\
\text { mean } \pm \mathrm{sd}\end{array}$ & $\begin{array}{l}\text { CRT }(\mathbf{n}=\mathbf{2 0}) \\
\text { mean } \pm s d\end{array}$ & $p$ Value \\
\hline Gender & $\begin{array}{r}14 \text { female } \\
9 \text { male }\end{array}$ & $\begin{array}{r}8 \text { female } \\
10 \text { male }\end{array}$ & $\begin{array}{c}7 \text { female } \\
13 \text { male }\end{array}$ & \\
\hline Ages (years) & $33.39 \pm 4.08$ & $34.33 \pm 4.41$ & $27.00 \pm 8.14$ & \\
\hline$M(D)$ & $-3.61 \pm 0.67$ & $-4.14 \pm 0.89$ & $-3.41 \pm 0.76$ & $0.020 *$ \\
\hline JO (D) & $0.07 \pm 0.21$ & $0.09 \pm 0.30$ & $0.02 \pm 0.20$ & $0.288 *$ \\
\hline J45 (D) & $0.00 \pm 0.20$ & $0.00 \pm 0.19$ & $-0.03 \pm 0.08$ & $0.854 *$ \\
\hline
\end{tabular}

* Kruskal Wallis Test; SL - standard LASIK; CL - custom LASIK and CRT - orthokeratology. M, J0 and J45 are refractive components. 
Table 2. Pretreatment, post treatment and difference (post-pre) values of elevation data for standard LASIK, custom LASIK and CRT (values are expressed in microns).

\begin{tabular}{|c|c|c|c|c|c|c|c|c|}
\hline & & \multicolumn{2}{|c|}{$S L(n=23)$} & \multicolumn{2}{|c|}{$C L(n=18)$} & \multicolumn{2}{|c|}{ CRT $(n=20)$} & \multirow[b]{2}{*}{$p^{b}$ value } \\
\hline & & mean $\pm s d$ & $\begin{array}{c}\text { post-pre } \\
p^{a} \text { value }\end{array}$ & mean $\pm s d$ & $\begin{array}{c}\text { post-pre } \\
\mathrm{p}^{\mathrm{a}} \text { value }\end{array}$ & mean $\pm s d$ & $\begin{array}{c}\text { post-pre } \\
p^{a} \text { value }\end{array}$ & \\
\hline \multicolumn{9}{|c|}{ Front elevation } \\
\hline \multirow{2}{*}{ N4 } & pre & $15.70 \pm 6.46$ & $29.17 \pm 5.89$ & $12.11 \pm 11.17$ & $35.17 \pm 12.57$ & $14.80 \pm 5.98$ & $1.50 \pm 4.27$ & $0.353+$ \\
\hline & post & $44.87 \pm 8.47$ & & $47.28 \pm 13.70$ & $<0.001 \S$ & $16.30 \pm 6.06$ & $0.133 \S$ & $<0.001+$ \\
\hline \multirow{2}{*}{ N3 } & pre & $2.17 \pm 3.37$ & $14.74 \pm 4.03$ & $0.50 \pm 5.06$ & $21.83 \pm 5.79$ & $3.60 \pm 4.67$ & $3.95 \pm 3.66$ & $0.099+$ \\
\hline & post & $16.91 \pm 4.17$ & $<0.001 \S$ & $22.33 \pm 6.56$ & $<0.001 \S$ & $7.55 \pm 5.26$ & $<0.001 \S$ & $<0.001+$ \\
\hline \multirow{2}{*}{ N2 } & pre & $0.04 \pm 2.34$ & $-6.26 \pm 2.94$ & $-0.56 \pm 1.79$ & $5.39 \pm 4.06$ & $1.50 \pm 4.11$ & $3.10 \pm 4.09$ & $0.088+$ \\
\hline & post & $-6.22 \pm 2.30$ & $<0.001 \S$ & $-5.94 \pm 4.50$ & $<0.001 \S$ & $4.60 \pm 4.57$ & $0.007 ¥$ & $<0.001^{*}$ \\
\hline \multirow{2}{*}{ N1 } & pre & $0.91 \pm 1.44$ & $-19.83 \pm 2.98$ & $0.50 \pm 0.86$ & $-24.56 \pm 6.75$ & $0.90 \pm 1.68$ & $-3.05 \pm 3.63$ & $0.634^{*}$ \\
\hline & post & $-18.91 \pm 2.81$ & $<0.001 \S$ & $-24.06 \pm 6.58$ & $<0.001 ¥$ & $-2.15 \pm 3.41$ & $0.001 \S$ & $<0.001+$ \\
\hline \multirow{2}{*}{ C } & pre & $1.70 \pm 1.02$ & $-24.04 \pm 3.84$ & $1.28 \pm 0.75$ & $-30.67 \pm 7.84$ & $0.60 \pm 2.46$ & $-7.85 \pm 5.48$ & $0.134^{*}$ \\
\hline & post & $-22.35 \pm 3.59$ & $<0.001 ¥$ & $-29.39 \pm 7.89$ & $<0.001 ¥$ & $-7.25 \pm 4.28$ & $<0.001 ¥$ & $<0.001+$ \\
\hline \multirow{2}{*}{$\mathrm{T} 1$} & pre & $2.57 \pm 1.53$ & $-19.39 \pm 3.55$ & $1.89 \pm 1.64$ & $-25.22 \pm 6.73$ & & $-6.65 \pm 5.51$ & $0.322^{*}$ \\
\hline & post & $-16.83 \pm 3.69$ & & $-23.33 \pm 7.05$ & & -4.80 & $<0.001 ¥$ & $<0.001+$ \\
\hline \multirow{2}{*}{$\mathrm{T} 2$} & pre & $2.65 \pm 2.60$ & $-5.78 \pm$ & $1.94 \pm 3.54$ & $-7.67 \pm 3.88$ & 2.65 & $-0.60 \pm 4.31$ & $0.267+$ \\
\hline & post & & & & & & & $<0.001^{*}$ \\
\hline \multirow{2}{*}{ T3 } & pre & & $14.48 \pm$ & & 18.28 & & $3.75 \pm$ & $0.290 *$ \\
\hline & post & $17.43 \pm 4.36$ & & $20.33 \pm 6.07$ & $01 \S$ & 7.15 & $36 ¥$ & $<0.001+$ \\
\hline \multirow{2}{*}{$\mathrm{T} 4$} & pre & $11.35 \pm 6.39$ & $29.57 \pm 5.94$ & $7.78 \pm 8.84$ & $37.78 \pm$ & 6.15 & $2.30 \pm$ & $0.253+$ \\
\hline & post & & & $45.56 \pm 12.02$ & $<0.001 \S$ & 11.0 & $0.224 \S$ & $01 *$ \\
\hline \multicolumn{9}{|c|}{ Back elevation } \\
\hline \multirow{2}{*}{ N4 } & pre & $28.61 \pm 14.21$ & $2.22 \pm 12.06$ & $27.17 \pm 16.93$ & $-3.67 \pm 12.00$ & $33.05 \pm 14.66$ & $-1.50 \pm 11.57$ & $0.456+$ \\
\hline & post & $26.39 \pm 12.98$ & $0.387 \S$ & $23.50 \pm 21.57$ & $0.212 \S$ & $31.55 \pm 14.89$ & $0.569 \S$ & $0.317+$ \\
\hline \multirow{2}{*}{ N3 } & pre & $5.61 \pm 7.32$ & $0.52 \pm 5.63$ & $7.61 \pm 9.38$ & $-0.78 \pm 5.97$ & $10.95 \pm 9.06$ & $-1.70 \pm 9.58$ & $0.130+$ \\
\hline & post & & & $6.83 \pm 10.45$ & & $9.25 \pm 8.62$ & $0.437 \S$ & $0.477+$ \\
\hline \multirow{2}{*}{ N2 } & pre & $6.39 \pm 4.88$ & $1.87 \pm 4.00$ & $7.17 \pm 5.44$ & $0.83 \pm 3.65$ & $10.25 \pm 6.38$ & $-0.65 \pm 7.11$ & $0.070+$ \\
\hline & post & $8.26 \pm 5.03$ & $0.036 \S$ & $8.00 \pm 7.10$ & $0.346 \S$ & $9.60 \pm 6.68$ & $0.687 \S$ & $0.690+$ \\
\hline \multirow{2}{*}{ N1 } & pre & $4.26 \pm 2.32$ & $0.83 \pm 3.55$ & $3.78 \pm 2.58$ & $0.83 \pm 3.60$ & $5.60 \pm 3.08$ & $-0.45 \pm 3.27$ & $0.096+$ \\
\hline & post & $5.09 \pm 3.44$ & $0.277 \S$ & $4.61 \pm 4.23$ & $0.340 \S$ & $5.15 \pm 4.25$ & $0.545 \S$ & $0.901+$ \\
\hline \multirow{2}{*}{ C } & pre & $2.00 \pm 3.16$ & $0.09 \pm 2.47$ & $0.83 \pm 1.62$ & $0.28 \pm 4.01$ & $1.25 \pm 2.49$ & $-0.90 \pm 3.43$ & $0.384^{*}$ \\
\hline & post & $2.09 \pm 3.67$ & $0.867 \S$ & $1.11 \pm 3.76$ & $0.772 \S$ & $0.35 \pm 4.88$ & $0.274 ¥$ & $0.390+$ \\
\hline \multirow{2}{*}{ T1 } & pre & $5.22 \pm 3.63$ & $0.65 \pm 2.33$ & $3.89 \pm 2.47$ & $0.67 \pm 3.33$ & $4.20 \pm 3.49$ & $-0.25 \pm 2.88$ & $0.395+$ \\
\hline & post & $5.87 \pm 3.47$ & $0.193 \S$ & $4.56 \pm 3.58$ & $0.407 \S$ & $3.95 \pm 5.33$ & & $0.314+$ \\
\hline \multirow{2}{*}{ T2 } & pre & $8.17 \pm 4.89$ & $1.04 \pm 3.89$ & $8.17 \pm 5.98$ & $1.44 \pm 2.15$ & $9.05 \pm 5.28$ & $1.55 \pm 3.68$ & $0.835+$ \\
\hline & post & $9.22 \pm 3.63$ & $0.212 \S$ & $9.61 \pm 6.10$ & $0.011 \S$ & $10.60 \pm 5.83$ & $0.075 \S$ & $0.677+$ \\
\hline \multirow{2}{*}{ T3 } & pre & $8.43 \pm 9.66$ & $-0.22 \pm 9.53$ & $9.89 \pm 11.04$ & $0.89 \pm 6.88$ & $12.25 \pm 8.44$ & $0.70 \pm 7.03$ & $0.441+$ \\
\hline & post & $8.22 \pm 6.80$ & & $10.78 \pm 12.43$ & $0.591 \S$ & $12.95 \pm 8.83$ & $0.661 \S$ & $0.264+$ \\
\hline \multirow{2}{*}{ T4 } & pre & $22.39 \pm 15.24$ & $-2.96 \pm 17.07$ & $21.06 \pm 15.73$ & $-2.94 \pm 13.98$ & $26.75 \pm 11.83$ & $-2.50 \pm 12.65$ & $0.437+$ \\
\hline & post & $19.43 \pm 15.31$ & $0.415 \S$ & $18.11 \pm 20.15$ & $0.384 \S$ & $24.25 \pm 13.55$ & $0.388 \S$ & $0.471+$ \\
\hline
\end{tabular}


C-center of corneal topography; N1, N2, N3, N4, 1-4mm in the nasal corneal and T1,T2, T3, T4, 1-4mm in the temporal corneal. SL - standard LASIK; CL - custom LASIK and CRT - orthokeratology. $p^{\text {a }}$ - statistically differences between post and pretreatment ( $§$ paired sample t-test, $¥$ Wilcoxon Signed Ranks Test). $p^{b}$ statistically differences among groups(+ANOVA, *Kruskal-Wallis Test).

Figure 1. Plots of corneal elevation of front corneal surface as a function of horizontal meridian obtained with relationship between difference treatment for standard myopic LASIK, for custom myopic LASIK and orthokeratology.

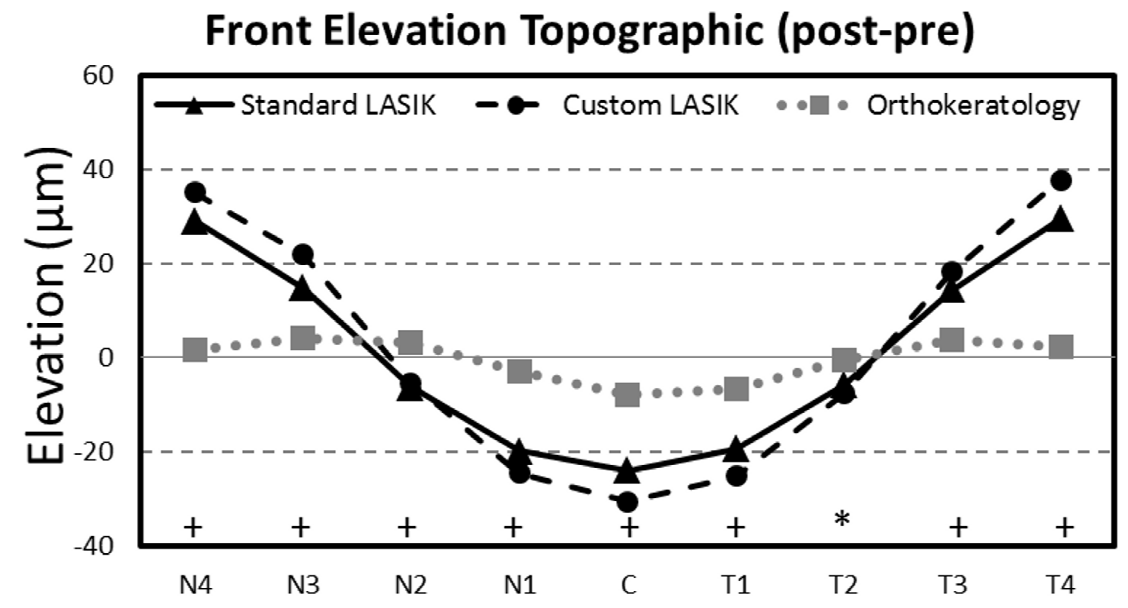

${ }^{+}$Analysis of variance (ANOVA); * Kruskal-Wallis Test; NS: non-significant; $\mu \mathrm{m}=$ microns.

Figure 2. Plots of corneal elevation of back corneal surface as a function of horizontal meridian obtained with relationship between difference treatment for standard myopic LASIK, for custom myopic LASIK and orthokeratology.

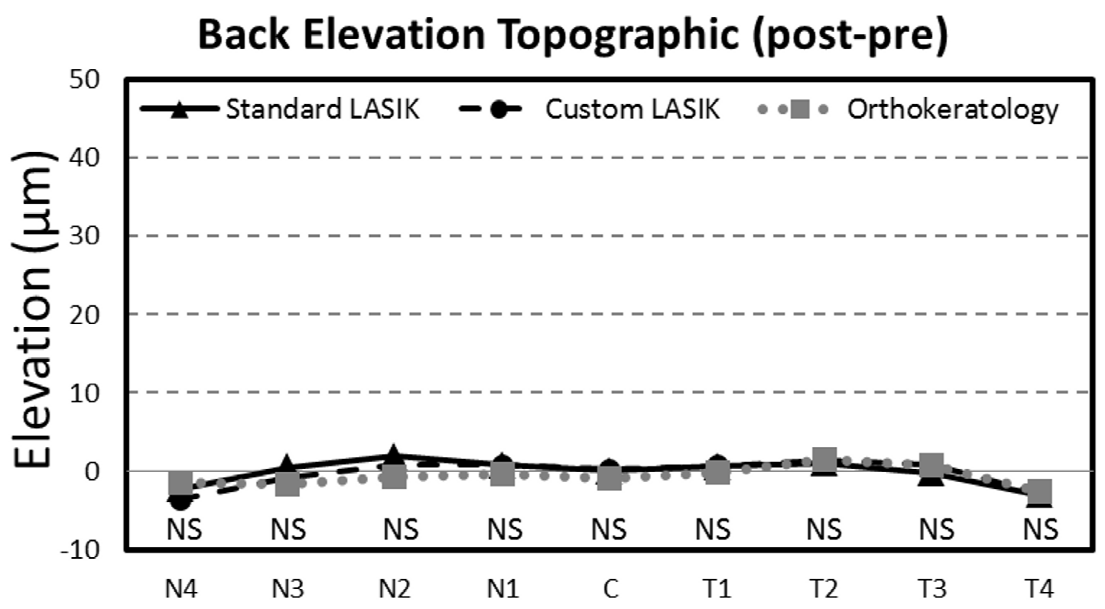

NS: non-significant; $\mu \mathrm{m}=$ microns. 


\section{Reference List}

1. Belin MW, Khachikian SS. An introduction to understanding elevation-based topography: how elevation data are displayed - a review. Clin Experiment Ophthalmol 2009;37:14-29.

2. Swartz T, Marten L, Wang M. Measuring the cornea: the latest developments in corneal topography. Curr Opin Ophthalmol 2007;18:325-33.

3. Read SA, Collins MJ, Iskander DR, Davis BA. Corneal topography with Scheimpflug imaging and videokeratography: comparative study of normal eyes. J Cataract Refract Surg 2009;35:1072-81.

4. Barkana Y, Gerber Y, Elbaz U et al. Central corneal thickness measurement with the Pentacam Scheimpflug system, optical low-coherence reflectometry pachymeter, and ultrasound pachymetry. J Cataract Refract Surg 2005;31:172935 .

5. Ucakhan OO, Ozkan M, Kanpolat A. Corneal thickness measurements in normal and keratoconic eyes: Pentacam comprehensive eye scanner versus noncontact specular microscopy and ultrasound pachymetry. J Cataract Refract Surg 2006;32:970-7.

6. Jain R, Dilraj G, Grewal SP. Repeatability of corneal parameters with Pentacam after laser in situ keratomileusis. Indian J Ophthalmol 2007;55:341-7.

7. Lu F, Simpson T, Sorbara L, Fonn D. The relationship between the treatment zone diameter and visual, optical and subjective performance in Corneal Refractive Therapy lens wearers. Ophthalmic Physiol Opt 2007;27:568-78.

8. Holladay JT, Dudeja DR, Chang J. Functional vision and corneal changes after laser in situ keratomileusis determined by contrast sensitivity, glare testing, and corneal topography. J Cataract Refract Surg 1999;25:663-9.

9. Gonzalez-Meijome JM, Villa-Collar C. Nomogram, corneal topography, and final prescription relations for Corneal Refractive Therapy. Optom Vis Sci 2007;84:59-64.

10. Chen D, Lam AK. Intrasession and intersession repeatability of the Pentacam system on posterior corneal assessment in the normal human eye. J Cataract Refract Surg 2007;33:448-54.

11. Pinero DP, Saenz GC, Alio JL. Intraobserver and interobserver repeatability of curvature and aberrometric measurements of the posterior corneal surface in normal eyes using Scheimpflug photography. J Cataract Refract Surg 2009;35:113-20.

12. Jain R, Dilraj G, Grewal SP. Repeatability of corneal parameters with Pentacam after laser in situ keratomileusis. Indian J Ophthalmol 2007;55:341-7.

13. Queiros A, Gonzalez-Meijome JM, Villa-Collar C, Gutierrez AR, Jorge J. Local steepening in peripheral corneal curvature after corneal refractive therapy and LASIK. Optom Vis Sci 2010;87:432-9. 
14. Swarbrick HA, Wong G, O'Leary DJ. Corneal response to orthokeratology. Optom Vis Sci 1998;75:791-9.

15. Alharbi A, Swarbrick HA. The effects of overnight orthokeratology lens wear on corneal thickness. Invest Ophthalmol Vis Sci 2003;44:2518-23.

16. Dupps WJ, Jr., Wilson SE. Biomechanics and wound healing in the cornea. Exp Eye Res 2006;83:709-20.

17. Alharbi A, La Hood D, Swarbrick HA. Overnight orthokeratology lens wear can inhibit the central stromal edema response. Invest Ophthalmol Vis Sci 2005;46:2334-40.

18. Grewal DS, Brar GS, Grewal SP. Posterior corneal elevation after LASIK with three flap techniques as measured by Pentacam. J Refract Surg 2011;27:261-8.

19. Ha BJ, Kim SW, Kim SW, Kim EK, Kim TI. Pentacam and Orbscan II measurements of posterior corneal elevation before and after photorefractive keratectomy. J Refract Surg 2009;25:290-5.

20. Naroo SA, Charman WN. Changes in posterior corneal curvature after photorefractive keratectomy. J Cataract Refract Surg 2000;26:872-8.

21. Rani A, Murthy BR, Sharma N et al. Posterior corneal topographic changes after retreatment LASIK. Ophthalmology 2002;109:1991-5.

22. Seitz B, Torres F, Langenbucher A, Behrens A, Suarez E. Posterior corneal curvature changes after myopic laser in situ keratomileusis. Ophthalmology 2001;108:666-72.

23. Baek T, Lee K, Kagaya F, Tomidokoro A, Amano S, Oshika T. Factors affecting the forward shift of posterior corneal surface after laser in situ keratomileusis. Ophthalmology 2001;108:317-20.

24. Nawa Y, Masuda K, Ueda T, Hara Y, Uozato H. Evaluation of apparent ectasia of the posterior surface of the cornea after keratorefractive surgery. J Cataract Refract Surg 2005;31:571-3.

25. Cheng AC, Ho T, Lau S, Lam DS. Evaluation of the apparent change in posterior corneal power in eyes with LASIK using Orbscan II with magnification compensation. J Refract Surg 2009;25:221-8.

26. Gonzalez-Meijome JM, Cervino A, Yebra-Pimentel E, Parafita MA. Central and peripheral corneal thickness measurement with Orbscan II and topographical ultrasound pachymetry. J Cataract Refract Surg 2003;29:125-32.

27. Perez-Escudero A, Dorronsoro C, Sawides L, Remon L, Merayo-Lloves J, Marcos S. Minor influence of myopic laser in situ keratomileusis on the posterior corneal surface. Invest Ophthalmol Vis Sci 2009;50:4146-54. 